Article

\title{
The Contribution of Mutual Grooming to Affiliative Relationships in a Feral Misaki Horse Herd
}

\author{
Masaki Shimada $*$ (D) and Nae Suzuki \\ Department of Animal Sciences, Teikyo University of Science, 2525 Yatsusawa, Yamanashi prefecture, \\ Uenohara 409-0193, Japan; agu_horse0731@yahoo.co.jp \\ * Correspondence: masakishimada@japan.email.ne.jp; Tel.: +81-554-63-6814; Fax: +81-554-63-4431
}

Received: 22 July 2020; Accepted: 31 August 2020; Published: 3 September 2020

Simple Summary: Social grooming strengthens affiliative relationships between participants in many social primates. Three hypotheses regarding the function of mutual grooming in feral horses were tested: the affiliative relationship strengthening hypothesis, the worsened relationship restoring hypothesis, and the parasite removal hypothesis. All the nine horses in the " $6 \mathrm{~m}$ " herd in a Misaki feral horse (Equus caballus) herd in Cape Toi, Japan, were investigated in terms of kinship, grooming, aggression, proximity, social rank, and social network. The correlations between mutual grooming and proximity and between aggression and proximity were established mathematically. Controlling for kinship, there were significant positive partial correlations between mutual grooming and proximity and between aggression and proximity. No correlation was observed between aggression and mutual grooming. Individuals that spent less time on self-grooming invested longer times receiving grooming from other individuals. In a feral horse population, mutual grooming maintains hygiene by controlling ectoparasites and forges affiliative interactions between herd members.

\begin{abstract}
Although herd size, structure, stability, and social rank among Misaki feral horses have been reported, no studies have been conducted on the affiliative relationships and interactions among members in a Misaki horse herd. The validity of three hypotheses regarding the function of social grooming, the affiliative relationship strengthening hypothesis, the worsened relationship restoring hypothesis, and the grooming parasite removal hypothesis, were tested in a Misaki feral horse (Equus caballus) herd in Cape Toi, Japan. All the nine horses in the " $6 \mathrm{~m}$ " herd were investigated in terms of kinship, grooming, aggression, proximity, social rank, and social network. Mutual grooming occurred only in pairs and was almost perfectly symmetrical. For each member, there was a significant negative correlation between total grooming received from other individuals and self-grooming. Controlling for kinship, there were significant positive partial correlations between mutual grooming and proximity and between aggression and proximity. No correlation was observed between aggression and mutual grooming. The results suggest that mutual grooming symmetry may contribute that both participants simultaneously benefit from parasite removal and strengthen affiliative relationships between seasonally changing herd members; however, mutual grooming did not foster restoring the worsened relationship following aggression promoted by physical proximity. The findings of this study may elucidate the mechanisms by which interactions between herd members are maintained or strengthened.
\end{abstract}

Keywords: Equus caballus; Misaki feral horse; affiliative relationship; mutual grooming; social rank

\section{Introduction}

In many mammals, individuals strengthen affiliative relationships with unrelated individuals to enhance their reproductive success [1-3]. Social grooming strengthens affiliative relationships 
between participants in many social primates [4-6]. Social grooming between primates is primarily asymmetrical $[7,8]$. Grooming exchanges continue over extended periods in groups with long-term stability [9-11]. Pairs that equalize the amount of social grooming in the long term maintain their affiliative relationships $[5,6]$.

Horses (Equus caballus) that have left human control and live in environments with minimal artificial control are known as feral [12]. Feral horses live in herds comprising one to a few adult males (stallions), several unrelated adult females (mares), and immature offspring of both sexes (fillies and colts) [13-17]. The social rank established among herd members shows long-term stability [18-20]. Both colts and fillies leave their natal herds at approximately 2-3 years of age. Fillies either remain unaffiliated with any one particular herd or migrate to another [21,22]. Colts either form bachelor herds [23-26] or will sequester mares to form their own herd [22]. Herd membership is stable during the breeding season between spring and autumn [25,27]; however, as in the case of Misaki feral horses in Japan, a herd may disperse in the winter, and its membership might fluctuate by the following spring [21,28]. Because feral horses maintain these basic social structures, they are a suitable model for studying whether social grooming contributes to the strengthening of affiliations within the herd.

Grooming behavior is broadly divided into self-grooming (auto-grooming) and mutual grooming (allo-grooming) [29-31]. Self-grooming consists of tail swishing, rolling, nipping, and rubbing on inanimate objects [29,32]. Mutual grooming generally occurs between two horses. They stand parallel to each other on the same side of the body and bite, lick, or pull their opponent's head, mane, back, and hindquarters $[16,23,33]$. Mutual grooming enables each participant to clean body parts they cannot reach on their own and lowers participant heart rates [14]. In horses, mutual grooming may be a typical affiliative behavior $[3,34]$ that strengthens long-term social relationships between unrelated mares [35] and is conciliatory after aggressive interactions [36]. There are multiple different hypotheses about the function of mutual grooming in horses. Adult feral mares may form affiliative relationships with other unrelated mares and stallions by mutual grooming, thereby reducing the number of aggressive interactions [2,26]. In Camargue horses in France, mutual grooming has never been observed between adult stallions but occurs between a stallion and a mare during the breeding season [14]. It is suggested that affiliative relationships between unrelated mares or stallions in a herd may increase reproductive success by reducing harassment from other mares or stallions [37]. Thus, it is hypothesized that strengthening the affiliation between unrelated horses by mutual grooming may increases reproductive success $[2,35,38]$. However, few empirical investigations have determined whether individuals that mutually groom have fewer aggressive interactions and build stronger affiliative relationships than individuals that do not mutually groom [3].

Affiliative relationships between pairs of horses may be indicated by the frequency of their close interactions $[16,33,35]$. Kinship and mutual grooming between herd members strengthens affiliative relationships $[2,16,24]$. It has been hypothesized that mutual grooming strengthens affiliative relationships between participating individuals $[3,35]$. Thus, a positive correlation is expected between mutual grooming frequency and proximity within the herd. Nevertheless, these parameters may differ between related and unrelated horses [2,39]. Therefore, it is necessary to control for pair kinship to verify this correlation [40].

Another hypothesis proposes that mutual grooming restores worsened relationships when aggressive interactions occur in pairs [36]. Thus, a positive correlation is expected between the frequency of aggressive interactions and mutual grooming in each pair. However, the frequency of aggressive interactions may be negatively correlated with the degree of kinship in each pair. Thus, it is necessary to control for pair kinship to verify this correlation.

Aggressive interactions may be byproducts of the physical proximity between individuals of different social rank [41,42]. In this case, a positive correlation is expected between the frequency of aggressive interactions and pair proximity. However, it is necessary to control for kinship to validate this prediction. 
Grooming is considered a maintenance behavior in horses. It removes ectoparasites such as lice and flies [32]. The grooming parasite removal hypothesis [29,32] suggests that mutual grooming removes parasites that cannot be removed by self-grooming alone. A negative correlation is expected between the total grooming time that each individual receives from other individuals (mutual grooming) and the total time spent for self-grooming.

The objective of the study was to clarify the role of mutual grooming within the feral herd by testing the aforementioned predictions derived from three hypotheses regarding the function of mutual grooming; the affiliative relationship strengthening hypothesis, the worsened relationship restoring hypothesis, and the grooming parasite removal hypothesis.

\section{Materials and Methods}

\subsection{Study Sites, Target Herd, and Study Period}

Misaki feral horses live in a protected $\sim 50$ ha area at Cape Toi, Kushima City, Miyazaki Prefecture, Japan [21,22,43]. The ranch there was opened in 1697 during the Edo era. The horses have bred in a half-wild environment with minimal human modification or intervention. Thus, original social constructs in behavior of feral horses can be observed there. The frequency of aggressive interactions between individual Misaki feral horses is low as they have sufficient food resources and living space throughout all seasons except winter [21,44]. Moreover, stallions form new herds by sequestering mares not belonging to any particular group [22]. Herd size, structure, stability [21,45,46], and social rank among Misaki feral horses [21] have been reported. Membership in each herd is stable throughout all seasons except winter $[21,28,46]$. However, no studies have considered the affiliative relationships and interactions within the herd. Many of the horses are accustomed to human observers and have been individually identified [21]. For these reasons, Misaki feral horses are considered to be suitable subjects for the analysis of individual herd member behavior and interactions between pairs in specific seasons.

As of 2018, there are 120 extant Misaki feral horses. They inhabit Komatsugaoka and Ogiyama, located at altitudes of $287 \mathrm{~m}$ and $296 \mathrm{~m}$, respectively, situated near the center of Cape Toi, Kushima City, Miyazaki Prefecture, Japan. The aforementioned regions have the largest total grassland area within the cape and constitute the main home range of Misaki feral horses [21]. The Misaki feral horse population is classified into 20 herds, several bachelor herds, and solitary bachelors. Individual identification, herd membership and composition, births, deaths, and maternal relationships have been recorded and made available by the research team of Miyazaki University for several decades.

One of the herds (the " $6 \mathrm{~m}$ " group) uses Komatsugaoka as their home range. All the nine members of the "6m" group were targeted for this survey (Table S1). During the study period, the "6m" group consisted of two stallions ("6m" and " $16 \mathrm{~m}$ "), one young adult male ("63m"), four unrelated adult mares ("73f," "90f," "20f," and "94f"), one colt (juvenile male) ("76m"), and one filly (juvenile female) ("75f"). No other members joined or left the herd during the survey.

The study was conducted during breeding season and the beginning of the non-breeding season of the Misaki feral horse [21,43]. The observation was planned to be conducted between 9:00 a.m. and 4:00 p.m. for 1-4 h per day, depending on the weather conditions. As a result, the observation was conducted for seven days for a total of $16.5 \mathrm{~h}$ on 9-17 May 2018, three days for a total of $6.0 \mathrm{~h}$ on 1-4 July 2018, and five days for a total of $11.0 \mathrm{~h}$ on October $4-8,2018$. The total observation time of the " $6 \mathrm{~m}$ " group was $33.5 \mathrm{~h}$ and the mean daily observation time ( $\pm \mathrm{SD}$ ) was $2.09 \pm 0.85 \mathrm{~h}$ (15 survey days).

\subsection{Behavioral Data Collection and Treatment}

\subsubsection{Kinship}

The kinship of the paternal lineage of Misaki feral horses is unknown. However, the maternal lineage was elucidated through birth records. The relatedness (r) among the members of the " $6 \mathrm{~m}$ " group was assumed to be 0.5 for individuals in mother-child relationships, and 0.25 for individuals 
in sibling relationships sharing a mother. The relatedness between individuals without a directly confirmed kinship was assigned to 0. A kinship matrix was constructed wherein the relatedness between pairs was used as each element.

The Misaki feral horses were highly aggregated during the study period [21,43,46]. N.S., the second author, tracked the "6m" group with a digital Handycam (SONY HDR-CX680; Sony Corporation, Tokyo, Japan) to videotape all members in the field of view simultaneously. Except during inclement weather, the herd was followed for $\sim 2 \mathrm{~h}$ each morning and afternoon daily. All self- and mutual grooming and aggressive interactions occurring within the herd were continuously recorded by the all occurrence sampling method [47].

\subsubsection{Grooming}

For both self- and mutual grooming, the start and end times and the individual who started and ended the behavior were recorded. The total time spent self-grooming by each individual was calculated in seconds from these data. Mutual grooming is expressed in terms of the asymmetrical state wherein individual $i$ grooms individual $j$ but not vice-versa, the symmetrical state wherein both $i$ and $j$ are grooming each other simultaneously, and the pausing state defined as an interruption in grooming that is resumed within $120 \mathrm{~s}$. If mutual grooming was resumed $>120 \mathrm{~s}$ after the interruption, it was defined as an independent bout. For each individual, the total amount of grooming received from other individuals during mutual grooming was reported as the sum of the asymmetrical and symmetrical states. A grooming matrix was constructed using the number of observed mutual grooming bouts throughout the study period in all pairs as elements.

\subsubsection{Aggression}

In aggressive interactions, an individual threatens or attacks another individual and/or the threatened or attacked individual retreats, flees, or avoids $[23,30,36]$. Threats include arched necks, stand-stares, and ears-laid-back. Attacks include biting, balking, and chase kicking [23,48]. For each aggressive interaction, when the individual being threatened or attacked escaped or avoided the attack, it was recorded as the loser and the attacking side was recorded as the winner. The interaction was scored a draw if an individual did not respond to an attack by another horse or escaped or avoided approaching the individual in the absence of an attack or threat. A winner/loser matrix was constructed by plotting the number of aggressive interaction wins, losses, and draws between pairs. An aggression matrix was plotted by using the number of aggressive interactions between pairs as elements.

The relative social rank among the members of the " $6 \mathrm{~m}$ " group was scaled from a winner/loser matrix by the Batchelder-Bershad-Simpson (BBS) method [49]. The s(i) of individual $i$ was calculated according to Equation (1) and each s(i) was corrected according to Equation (2) to obtain $\mathrm{s}^{\prime}(i)$. Individuals with a larger s' $(i)$ were regarded as higher-ranked:

$$
\begin{gathered}
s(i)=\frac{\sqrt{2 \pi}\left(2 W_{i}-N_{i}\right)}{2 N_{i}} \\
\mathrm{~s}^{\prime}(i)=\left[\frac{2\left(W_{i}-L_{i}\right)}{N_{i}}\right]+Q_{i}
\end{gathered}
$$

where $W_{i}$ is the total number of aggressive interactions won by individual $i, N_{i}$ is the total number of aggressive interactions involving $i, L_{i}$ is the total number of aggressive interactions lost by $i$, and $Q_{i}$ is the average $s(i)$ for all individuals engaged in aggressive interactions with $i$.

\subsubsection{Proximity Matrices, Social Rank, and Social Network Analysis}

The nearest neighbor of each individual was recorded at 5 min intervals by the instantaneous sampling method [46]. The proximity index $\left(P I_{i j}\right)$ of a pair of individuals $i$ and $j$ was defined as a simple proximity index [40] and calculated using Equation (3). The PI of each pair has a value from 
$0-1$ and indicated the relative height of the proximity frequency for the pair in the " $6 \mathrm{~m}$ " group [40]. It represents the relative strength of the affiliative relationship of the pair [16,33,35].

$$
P I_{i j}=\frac{C_{i}(j)+C_{j}(i)}{T_{i}+T_{j}}
$$

where $C_{i}(j)$ is the total number of sample points where $j$ is the nearest neighbor to $i$, and $T_{i}$ is the total number of sample points for $i$. A proximity matrix was constructed using the PI among all pairs as elements.

The social network was based on the proximity relationship between pairs in the " $6 \mathrm{~m}$ " group. In a herd comprising nine individuals, there were $36(=9 \times 8 / 2)$ pairs or combinations of two members. The PIs were filtered such that only the values exceeding the mean + SD of all PIs for 36 pairs remained. These pairs were regarded as the proximity relationships representing the " $6 \mathrm{~m}$ " group [40]. A social network was constructed according to the filtered PIs. The eigenvector centrality for each individual was calculated according to the social network.

\subsection{Statistical Analyses}

The relationship between mutual grooming and proximity for each pair was evaluated. The correlation between the grooming and proximity matrices was determined using Kendall's tau correlation test (Tau $\mathrm{Kr}$ test). The kinship matrix served as the control and the correlation between the aforementioned matrices was then calculated with a matrix rank partial correlation test (partial Tau $\mathrm{Kr}$ test) [50,51]. The relationships between aggressive interactions and pair proximity, and between mutual grooming and aggressive interactions were examined as described above. For each test, the row or column randomization number was 100,000 .

The relationship between the amount of self-grooming and mutual grooming of each individual, as well as the relationship between centrality in the social network and social rank of each individual, was examined by regression analysis ( $F$-test). In the former analysis, the objective variable was the total time of self-grooming observed for each individual and the explanatory variable was the total time of grooming received from other individuals during mutual grooming. In the latter analysis, the objective variable was the eigenvector centrality of each individual and the explanatory variable was $s^{\prime}$.

All data were processed using the statistical freeware HAD [52], UCINET, NetDraw 2.166 [53], and MatrixtesterPrj [50]. The significance level was 0.05 .

\subsection{Ethical Approval}

Our research was approved by the Teikyo University of Science Animal Committee (No. 18C015) and permitted by Kushima City, Miyazaki Prefecture. Our behavioral research adhered to the guidelines of the International Society for Applied Ethology (http://www.applied-ethology.org/ethicalguidelines. $\mathrm{htm}$ ) for the ethical use of animals.

\section{Results}

\subsection{Mutual Grooming Interaction Structure}

The kinship, mutual grooming, aggression, and proximity matrices are shown in Tables $1-4$, where rows and columns refer to consecutive names given to males $(m)$ and females (f).

Self-grooming was observed in all " $6 \mathrm{~m}$ " herd members. The mean total time $( \pm S D)$ spent by each individual in self-grooming during the study period was $2174.8 \pm 1346.6 \mathrm{~s}(N=9)$. (Table S2).

Mutual grooming was confirmed for $6 / 9$ horses: two stallions (" $6 \mathrm{~m}$ " and " $16 \mathrm{~m}$ "), three adult mares ("20f," "73f," and "90f"), and one colt ("76m"). There were 84 bouts (Table 2). All observed mutual grooming bouts occurred only between two individuals from start to finish. In no instance did a third individual join a grooming pair. The mean total time $( \pm S D)$ spent by each individual in self-grooming 
during the study period was $477.0 \pm 351.5 \mathrm{~s}(N=9)$ (Table S2). The mean duration of a single mutual grooming bout was $84.8 \pm 80.5 \mathrm{~s}(\mathrm{~N}=34$; range $3-314 \mathrm{~s})$. In one bout, the symmetrical state $(62.4 \pm 54.7 \mathrm{~s})$ was linked to a pausing state $(21.0 \pm 33.7 \mathrm{~s})$ or short asymmetrical state $(1.4 \pm 4.0 \mathrm{~s})$. The total duration of symmetrical and asymmetrical grooming was $2123 \mathrm{~s}(97.8 \%)$ and $47 \mathrm{~s}(2.2 \%)$, respectively.

There was a significant negative correlation between the total time each individual spent in self-grooming and the total time each individual was groomed by another in mutual grooming (Table S2: $\beta=-0.195 ; R^{2}=0.559 ; F_{1,7}=8.888 ; p=0.020$ ).

Table 1. Kinship matrix.

\begin{tabular}{|c|c|c|c|c|c|c|c|c|c|}
\hline & $6 \mathrm{~m}$ & $16 \mathrm{~m}$ & $63 \mathrm{~m}$ & $20 f$ & $73 f$ & $90 \mathrm{f}$ & $94 \mathrm{f}$ & $75 f$ & $76 \mathrm{~m}$ \\
\hline $6 \mathrm{~m}$ & & 0 & 0 & 0 & 0 & 0 & 0 & 0 & 0 \\
\hline $16 \mathrm{~m}$ & & & 0 & 0 & 0 & 0 & 0 & 0 & 0 \\
\hline $63 \mathrm{~m}$ & & & & 0 & 0.5 & 0 & 0 & 0.25 & 0.25 \\
\hline $20 \mathrm{f}$ & & & & & 0 & 0 & 0 & 0 & 0 \\
\hline $73 \mathrm{f}$ & & & & & & 0 & 0 & 0.5 & 0.5 \\
\hline $90 \mathrm{f}$ & & & & & & & 0 & 0 & 0 \\
\hline $94 \mathrm{f}$ & & & & & & & & 0 & 0 \\
\hline $75 \mathrm{f}$ & & & & & & & & & 0.25 \\
\hline $76 \mathrm{~m}$ & & & & & & & & & \\
\hline
\end{tabular}

Table 2. Grooming matrix (mean $=0.944 ; \mathrm{SD}=0.472)$.

\begin{tabular}{|c|c|c|c|c|c|c|c|c|c|}
\hline & $6 \mathrm{~m}$ & $16 \mathrm{~m}$ & $63 \mathrm{~m}$ & $20 \mathrm{f}$ & $73 \mathrm{f}$ & $90 \mathrm{f}$ & $94 \mathrm{f}$ & $75 \mathrm{f}$ & $76 \mathrm{~m}$ \\
\hline $6 \mathrm{~m}$ & & 0 & 0 & 6 & 4 & 1 & 0 & 0 & 1 \\
\hline $16 \mathrm{~m}$ & & & 0 & 0 & 3 & 3 & 0 & 0 & 3 \\
\hline $63 \mathrm{~m}$ & & & & 0 & 0 & 0 & 0 & 0 & 0 \\
\hline $20 \mathrm{f}$ & & & & & 0 & 6 & 0 & 0 & 1 \\
\hline $73 \mathrm{f}$ & & & & & & 0 & 0 & 0 & 2 \\
\hline $90 \mathrm{f}$ & & & & & & & 0 & 0 & 4 \\
\hline $94 \mathrm{f}$ & & & & & & & & 0 & 0 \\
\hline $75 f$ & & & & & & & & & 0 \\
\hline $76 \mathrm{~m}$ & & & & & & & & & \\
\hline
\end{tabular}

Table 3. Proximity matrix $($ mean $=0.125 ; S D=0.014)$.

\begin{tabular}{|c|c|c|c|c|c|c|c|c|c|}
\hline & $6 \mathrm{~m}$ & $16 \mathrm{~m}$ & $63 m$ & $20 \mathrm{f}$ & $73 f$ & $90 f$ & $94 \mathrm{f}$ & $75 \mathrm{f}$ & $76 \mathrm{~m}$ \\
\hline $6 \mathrm{~m}$ & & 0.2383 & 0.0622 & 0.2313 & 0.1775 & 0.1225 & 0.1328 & 0.0687 & 0.0523 \\
\hline $16 \mathrm{~m}$ & & & 0.0359 & 0.0514 & 0.0982 & 0.0741 & 0.1166 & 0.0734 & 0.0619 \\
\hline $63 m$ & & & & 0.1274 & 0.2988 & 0.0691 & 0.1294 & 0.1843 & 0.1357 \\
\hline $20 \mathrm{f}$ & & & & & 0.0544 & 0.3393 & 0.1601 & 0.0839 & 0.0660 \\
\hline $73 f$ & & & & & & 0.0798 & 0.0779 & 0.1141 & 0.1769 \\
\hline $90 f$ & & & & & & & 0.2323 & 0.0705 & 0.0566 \\
\hline $94 f$ & & & & & & & & 0.0967 & 0.0599 \\
\hline $75 \mathrm{f}$ & & & & & & & & & 0.2889 \\
\hline $76 \mathrm{~m}$ & & & & & & & & & \\
\hline
\end{tabular}


Table 4. Aggression matrix $($ mean $=4.444 ; \mathrm{SD}=0.722)$.

\begin{tabular}{|c|c|c|c|c|c|c|c|c|c|}
\hline & $6 \mathrm{~m}$ & $16 \mathrm{~m}$ & $63 \mathrm{~m}$ & $20 \mathrm{f}$ & $73 \mathrm{f}$ & $90 f$ & $94 \mathrm{f}$ & $75 f$ & $76 \mathrm{~m}$ \\
\hline $6 \mathrm{~m}$ & & 24 & 10 & 13 & 9 & 7 & 14 & 6 & 0 \\
\hline $16 \mathrm{~m}$ & & & 4 & 3 & 1 & 3 & 3 & 2 & 4 \\
\hline $63 \mathrm{~m}$ & & & & 0 & 0 & 5 & 10 & 1 & 2 \\
\hline $20 \mathrm{f}$ & & & & & 2 & 6 & 0 & 0 & 0 \\
\hline $73 \mathrm{f}$ & & & & & & 6 & 3 & 1 & 0 \\
\hline $90 \mathrm{f}$ & & & & & & & 12 & 4 & 2 \\
\hline $94 \mathrm{f}$ & & & & & & & & 1 & 1 \\
\hline $75 \mathrm{f}$ & & & & & & & & & 1 \\
\hline $76 \mathrm{~m}$ & & & & & & & & & \\
\hline
\end{tabular}

\subsection{Social Relationships and Interactions Among "6m" Herd Members}

A winner/loser matrix is shown in Table S3. The $s^{\prime}$ for each member was calculated from the winner/loser matrix by the BBS method. Both $s^{\prime}$ and the social rank based on $s^{\prime}$ are shown in Table S2. " $6 \mathrm{~m}$ " was the first-ranked individual. The $s$ ' values of the second- to fourth-ranked individuals did not differ and were classified into the upper-ranked group ("73f," "90f," and "16m"). The fifthand sixth-ranked individuals were categorized into the middle-ranked group ("20f" and "94f"). The seventh- to ninth-ranked individuals were placed in the lower-ranked group ("63m," "76m," and "75f") (Table S2).

The PIs among all " $6 \mathrm{~m}$ " members were $>0$ (Table 3$)$. For ten pairs, $P I>$ mean $+\mathrm{SD}(=0.1387)$. According to the PI between pairs, the social network of the " $6 \mathrm{~m}$ " group was structured such that the first-ranked male (" $6 \mathrm{~m}$ ") occupied the central position and connected to three different subgroups (Figure 1). The first subgroup consisted of "16m," which was the second-ranked male. It was observed that " $6 \mathrm{~m}$ " repeatedly and frequently directed aggressive behavior against " $16 \mathrm{~m}$ " and ultimately drove him out of the herd. The second subgroup comprised the related herd members, namely, a mother ("73f") and her offspring ("63m," "75f," and "76m"). The third subgroup contained three unrelated mares ("20f," "90f," and "94f"). The PI between "20f" and "90f" was the highest for the entire " $6 \mathrm{~m}$ " group (Table 3). No significant correlation was found between the social network eigenvector centrality and the rank $\left(s^{\prime}\right)$ of each individual $\left(\beta=0.063 ; R^{2}=0.330 ; F_{1,7}=3.448 ; p=0.106\right)$.

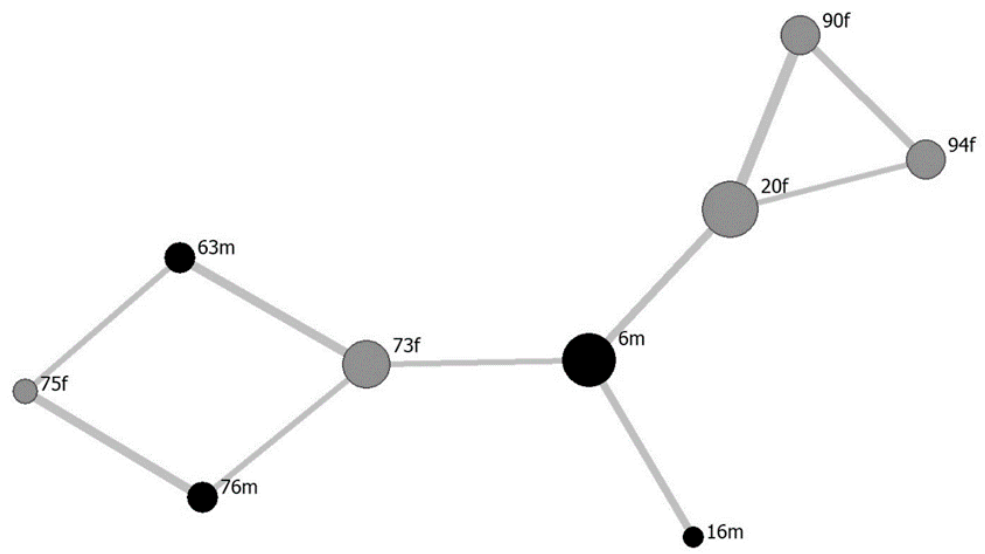

Figure 1. Social network based on proximity index of the " $6 \mathrm{~m}$ " herd. Black points represent males; "6m" and " $16 \mathrm{~m}$ " are stallions, " $63 \mathrm{~m}$ " is young male, and " $76 \mathrm{~m}$ " is a colt. Gray points represent mares; "73f," "90f," "20f," and "94f" are mares, and "75f" is a filly. Size of the point represents the magnitude of the centrality of the eigenvector and thickness of the line represents the degree of proximity between individuals. 


\subsection{Tau Kr Test}

No significant correlation was found between the kinship and grooming matrices (Figure 2: Tau $K r=-0.218 ; p=0.3040)$. A significant negative correlation was found between the kinship and aggression matrices (Tau $\mathrm{Kr}=-0.382 ; p=0.0498$ ). A significant positive correlation was found between the kinship and proximity matrices (Figure 2: Tau $K r=0.652 ; p=0.0079$ ).

No significant correlation was found between the grooming and proximity matrices (Figure 2: Tau $K r=0.136$; $p=0.2050$ ); however, a positive partial correlation was found between them when correcting for kinship (Figure 2: partial Tau $K r=0.376 ; p=0.0154$ ). The correlation between the aggression and grooming matrices was not significant (Tau $K r=-0.061 ; p=0.3687$ ). No partial correlation was found between them even after kinship correction (partial Tau $K r=-0.160 ; p=0.2049$ ). No significant positive correlation was found between the aggression and proximity matrices (Tau $K r=0.047 ; p=0.3364$ ); however, a significant partial correlation was found between them after correcting for kinship (partial Tau $K r=0.422 ; p=0.0003$ ).

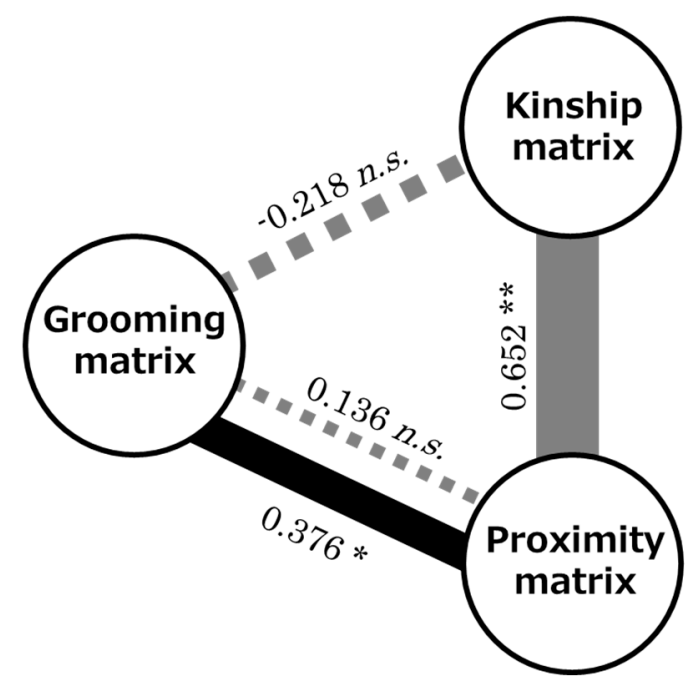

Figure 2. Correlation diagram of the matrices. Solid gray lines and the boldness indicate significant matrix rank correlations and coefficients (Tau $K r$ ), respectively, dotted lines indicate non-significant correlations, and black lines and the boldness indicate partial correlations and coefficients, respectively. The respective coefficients are shown above the line. ${ }^{*}$ indicates $p<0.05$ and ${ }^{* *}$ indicates $p<0.01 . n$. s. denotes a nonsignificant $(p>0.05)$.

\section{Discussion}

\subsection{Social Structure and Social Ranking in the " $6 m$ " Herd}

The social network of the " $6 \mathrm{~m}$ " group based on its proximity relationships had a structure centered on "6m," who was connected to three different subgroups. Individuals with higher ranks did not necessarily have higher group eigenvector centrality. Only those in the upper ranks were in proximity to "6m/" The middle-ranked individuals, "90f" and "94f," maintained proximity to "6m", mediated by the upper-ranked individual "20f." All three lower-ranked individuals were siblings of '73f' and had proximity to each other. The proximity between " $73 \mathrm{f}$ " and " $6 \mathrm{~m}$ " indirectly maintained those between the lower-ranked individuals and " $6 \mathrm{~m}$ " (Figure 1 ). The closest proximity was found between the oldest female "20f" and the unrelated young adult female "90f." Female mutual grooming was confirmed only between "20f" and "90f."

These results corroborate those of previous reports. Individual feral horses of similar rank on Yururi Island in Hokkaido maintain proximity to each other [16,24,33], as do Misaki feral horses [21]. Horses forming strong affiliative relationships might mutually groom each other within a herd [16]. 
These results suggest that during the study period, the group with " $6 \mathrm{~m}$ " as the highest rank individual was a typical herd with characteristics resembling those described in previous studies.

\subsection{Mutual Grooming And Affiliative Relationships between Horses}

A significant positive partial correlation was found between the grooming and proximity matrices when kinship was controlled. This finding upholds the affiliative relationship strengthening hypothesis. A significant positive correlation was also found between the aggression and proximity matrices when kinship was controlled. This result supports the hypothesis that proximity facilitates aggressive interactions between pairs. In contrast, no significant correlation was found between the aggression and grooming matrices here and the worsened relationship restoring hypothesis was not corroborated.

On Yururi Island in Japan, the individual free-ranging horses most often in proximity differ from those frequently engaging in mutual grooming [16]. The current results were similar to those of the aforementioned study but only when not correcting for kinship. The proximity and grooming matrices were not correlated. However, the horses on Yururi Island were members of a family herd [30]. Therefore, it is presumed that they were all related to each other and it would be impossible to analyze their proximity and mutual grooming while controlling for their kinship. When correcting for kinship in the present study, a positive correlation between proximity and mutual grooming was found. This discovery corroborates a previous report stating that proximity is correlated with mutual grooming between pairs of horses in the Serra d'Arga Mountain of Portugal [54].

If mutual grooming frequency increases with pair proximity, then mutual grooming frequency and aggressive interactions should be positively correlated. However, no significant correlation was found between aggression and mutual grooming between members of the " $6 \mathrm{~m}$ " group in the present study. The results of this study did not enable the estimation of the causal relationships of the effects of interactions between pairs on affiliative relationships. Pairs of related or unrelated individuals that frequently participate in mutual grooming have closer proximity [16]. Consequently, the risk of aggressive interactions increases between individuals differing in rank and physical proximity [42]. The first-ranked male " $6 \mathrm{~m}$ " and the second-ranked male " $16 \mathrm{~m}$ " were in proximity, but the former unilaterally attacked and repelled the latter, and there was no mutual grooming between them. Proximity, then, implies the potential for aggressive interactions between members of a pair and depends on the pair combination rather than their affiliative relationship.

The present study also upheld the parasite removal hypothesis. Individuals that spent less time on self-grooming invested longer times receiving grooming from other individuals. This discovery may suggest that mutual grooming has not only an aforementioned social function, such as strengthening affiliative relationships, but also a maintenance function, such as parasite removal [31,32].

In mutual grooming, both horses benefit from hygienic maintenance as they both groom and are groomed $[55,56]$. Here, mutual grooming between members of the " $6 \mathrm{~m}$ " group was performed symmetrically for the majority of the observations. Thus, mutual grooming between horses was almost completely and perfectly symmetrical. One horse received grooming from the other as soon as the former started grooming the latter. As soon as one horse stopped grooming, the other stopped as well. These behaviors applied both to related and unrelated pairs of horses. In all cases, the horses faced each other and mutually groomed nearly the same body parts simultaneously [16,33]. In this manner, each animal would receive an equal benefit regarding the simultaneous removal of parasites [56]. However, since this study did not take into account the different parasite loads for different individuals, receiving the same amount of mutual grooming may not be of the same benefit to all individuals. Future research needs to determine the amount of mutual grooming that takes into account the parasite load of each individual.

Mutual grooming between two primates strengthens affiliative relationships as they must both actively maintain interaction symmetry $[1,4,5,56]$. Thus, reciprocal altruism is characteristic of primate grooming. In contrast, asymmetrical social grooming is relatively less effective at strengthening affiliative relationships in species forming groups in which memberships rapidly and/or frequently 
fluctuate. The members of Misaki feral horse herds may change annually and numerous mares have indeterminate herd affiliations $[16,43,46]$. Symmetrical mutual grooming might ensure immediate parasite removal reciprocity and help forge affiliative relationships between unrelated individuals.

\section{Conclusions}

The present study supported the strengthening affiliative relationship and parasite removal hypotheses but did not corroborate the relationship restoring hypothesis. However, this study is merely a single case report based on relatively short observations made for one Misaki feral horse herd group when they were highly aggregated during a particular season. The aforementioned hypotheses must be tested on multiple herds and in longer-term observations of Misaki and other feral horses worldwide and can be extrapolated to understand behavioral stereotypies in horses in intensive production systems. The findings of this study suggest that comparisons between horses and other taxa, such as primates, may effectively elucidate the mechanisms by which interactions between group members maintain and strengthen their social relationships [15,54,57].

Supplementary Materials: The following are available online at http://www.mdpi.com/2076-2615/10/9/1564/s1, Table S1. Sex, age at time of study period, kinship, and total observation time for " $6 \mathrm{~m}$ " herd members.; Table S2. Frequency of aggressive interaction, s', eigenvector centrality, and total durations of self-grooming (min) and mutual grooming ( $\mathrm{min}$ ); Table S3. Winner/loser matrix. Left column shows name of winning individual. Top row shows name of losing individual. Numerical value at upper right of diagonal component indicates number of wins. Numerical value at lower left indicates number of losses-indicates no aggressive interaction observed in pair. The number in parentheses represents the number of aggressive interactions that ended in a draw.

Author Contributions: This study was designed by N.S. for a graduate thesis for a bachelor's degree under submission of M.S.; the manuscript was originally written by N.S. in Japanese and reviewed and translated into English by M.S.; N.S. collected behavioral data. and M.S. analyzed data statistically. All authors have read and agreed to the published version of the manuscript.

Funding: This work was partially supported by a MEXT Grant-in-Aid (KAKENHI) [grant numbers 20H01409].

Acknowledgments: We thank Hidetoshi Suwa, a horse guard, and Hiroyuki Odawara, director of the Cape Toi Maki Association for their participation in this study. We also thank Yukita Akita of Kushima City for the research permit application and acquisition. This study was approved by the Teikyo University of Science Animal Committee (No. 18C015).

Conflicts of Interest: The authors declare no conflict of interest. The funders had no role in the design of the study; in the collection, analyses, or interpretation of data; in the writing of the manuscript, or in the decision to publish the results.

\section{References}

1. Silk, J.B. The adaptive value of sociality in mammalian groups. Philos. Trans. R. Soc. Lond. B Biol. Sci. 2007, 362, 539-559. [CrossRef] [PubMed]

2. Cameron, E.Z.; Setsaas, T.H.; Linklater, W.L. Social bonds between unrelated females increase reproductive success in feral horses. Proc. Natl. Acad. Sci. USA 2009, 106, 13850-13853. [CrossRef] [PubMed]

3. Costa, H.; Fragoso, S.; Heitor, F. The relevance of affiliative relationships in horses: Review and future directions. Pet Behav. Sci. 2019, 8, 11-26. [CrossRef]

4. Seyfarth, R.M. A model of social grooming among adult female monkeys. J. Theor. Biol. 1977, 65, 671-698. [CrossRef]

5. Schino, G.; Aureli, F. Primate reciprocity and its cognitive requirements. Evol. Anthr. Iss News Rev. 2010, 19, 130-135. [CrossRef]

6. Silk, J.B.; Beehner, J.C.; Bergman, T.J.; Crockford, C.; Engh, A.L.; Moscovice, L.R.; Wittig, R.M.; Seyfarth, R.M.; Cheney, D.L. Female chacma baboons form strong, equitable, and enduring social bonds. Behav. Ecol. Sociobiol. 2010, 64, 1733-1747. [CrossRef] [PubMed]

7. Furuya, Y. Grooming behavior in the wild Japanese monkeys. Primates 1957, 1, 47-72. [CrossRef]

8. Inoue, N.; Shimada, M. Comparison of the activity budget, interactions, and social structure of captive and wild chimpanzees. Animals 2020, 10, 1063. [CrossRef]

9. Furuichi, T. Symmetrical patterns in non-agonistic social interactions found in unprovisioned Japanese macaques. J. Ethol. 1984, 2, 109-119. [CrossRef] 
10. Muroyama, Y. Mutual reciprocity of grooming in female japanese macaques (Macaca Fuscata). Behaviour 1991, 119, 161-170. [CrossRef]

11. Gomes, C.M.; Mundry, R.; Boesch, C. Long-term reciprocation of grooming in wild West African chimpanzees. Proc. Biol. Sci. 2009, 276, 699-706. [CrossRef] [PubMed]

12. Mills, D.S.; McDonnell, S.M. The Domestic Horse: The Origins, Development and Management of its Behaviour; Cambridge University Press: Cambridge, UK; New York, NY, USA, 2005.

13. Salter, R.E.; Hudson, R.J. Feeding Ecology of Feral Horses in Western Alberta. J. Range Manag. 1979, $32,221$. [CrossRef]

14. Feh, C.; de Mazières, J. Grooming at a preferred site reduces heart rate in horses. Anim. Behav. 1993, 46, 1191-1194. [CrossRef]

15. Ringhofer, M.; Inoue, S.; Mendonça, R.S.; Pereira, C.; Matsuzawa, T.; Hirata, S.; Yamamoto, S. Comparison of the social systems of primates and feral horses: Data from a newly established horse research site on Serra D'Arga, northern Portugal. Primates 2017, 58, 479-484. [CrossRef]

16. Kimura, R. Mutual grooming and preferred associate relationships in a band of free-ranging horses. Appl. Anim. Behav. Sci. 1998, 59, 265-276. [CrossRef]

17. Linklater, W.L.; Cameron, E.Z.; Stafford, K.J.; Veltman, C.J. Social and spatial structure and range use by Kaimanawa wild horses (Equus caballus: Equidae). New Zealand J. Ecol. 2000, 24, 139-152.

18. Houpt, K.A.; Law, K.; Martinisi, V. Dominance hierarchies in domestic horses. Appl. Anim. Ethol. 1978, 4, 273-283. [CrossRef]

19. Vervaecke, H.; Stevens, J.M.G.; Vandemoortele, H.; Sigurjónsdóttir, H.; De Vries, H. Aggression and dominance in matched groups of subadult Icelandic horses (Equus caballus). J. Ethol. 2006, 25, 239-248. [CrossRef]

20. Hartmann, E.; Christensen, J.W.; McGreevy, P.D. Dominance and Leadership: Useful Concepts in Human-Horse Interactions? J. Equine Vet. Sci. 2017, 52, 1-9. [CrossRef]

21. Kaseda, Y. The structure of the groups of misaki horses in toi cape. Nihon Chikusan Gakkaiho 1981, 52, $227-235$. [CrossRef]

22. Khalil, A.; Murakami, N. Factors Affecting the Harem Formation Process by Young Misaki Feral Stallions. J. Vet. Med. Sci. 1999, 61, 667-671. [CrossRef] [PubMed]

23. McDonnell, S.M.; Haviland, J.C.S. Agonistic ethogram of the equid bachelor band. Appl. Anim. Behav. Sci. 1995, 43, 147-188. [CrossRef]

24. Sigurjónsdóttir, H.; van Dierendonck, M.C.; Snorrason, S.; Thórhallsdóttir, A.G. Social relationships in a group of horses without a mature stallion. Behaviour 2003, 140, 783-804. [CrossRef]

25. Feh, C. Alliances and reproductive success in Camargue stallions. Anim. Behav. 1999, 57, 705-713. [CrossRef]

26. Linklater, W.L.; Cameron, E.Z. Tests for cooperative behaviour between stallions. Anim. Behav. 2000, 60, 731-743. [CrossRef]

27. Feh, C. Relationships and communication in socially. In The Domestic Horse: The Origins, Development and Management of its Behaviour; Mills, D.S., McDonnell, S.M., McDonnell, S., Eds.; Cambridge University Press: Cambridge, UK, 2005; pp. 83-93.

28. Imanishi, K. Social life of semi-wild horses in Toimisaki. Annu. Anim. Psychol. 1953, 3, 11-31. [CrossRef]

29. Boyd, L.E.; Carbonaro, D.A.; Houpt, K.A. The 24-hour time budget of Przewalski horses. Appl. Anim. Behav. Sci. 1988, 21, 5-17. [CrossRef]

30. McDonnell, S.M. A Practical Field Guide to Horse Behavior. The Equid Ethogram; Blood-Horse Publications: Lexington, KY, USA, 2003.

31. Mooring, M.S.; Blumstein, D.T.; Stoner, C.J. The evolution of parasite-defence grooming in ungulates. Biol. J Linn. Soc. 2004, 81, 17-37. [CrossRef]

32. Houpt, K.A. Maintenance behaviours. In The Domestic Horse: The Origins, Development and Management of its Behaviour; Mills, D.S., McDonnell, S.M., McDonnell, S., Eds.; Cambridge University Press: Cambridge, UK, 2005; pp. 94-109.

33. Wells, S.M.; Goldschmidt-Rothschild, B. Social behaviour and relationships in a herd of camargue horses. Z. FüR Tierpsychol. 1979, 49, 363-380. [CrossRef]

34. Briard, L.; Dorn, C.; Petit, O. Personality and Affinities Play a Key Role in the Organisation of Collective Movements in a Group of Domestic Horses. Ethology 2015, 121, 888-902. [CrossRef] 
35. Arnold, G.W.; Grassia, A. Ethogram of agonistic behaviour for thoroughbred horses. Appl. Anim. Ethol. 1982, 8, 5-25. [CrossRef]

36. Cozzi, A.; Sighieri, C.; Gazzano, A.; Nicol, C.J.; Baragli, P. Post-conflict friendly reunion in a permanent group of horses (Equus caballus). Behav. Process. 2010, 85, 185-190. [CrossRef] [PubMed]

37. Linklater, W.L.; Cameron, E.Z.; Minot, E.O.; Stafford, K.J. Stallion harassment and the mating system of horses. Anim. Behav. 1999, 58, 295-306. [CrossRef] [PubMed]

38. Klingel, H. Social organization and reproduction in equids. J. Reprod. Fertil. 1975, 23, 7-11.

39. Keiper, R.R.; Sambraus, H.H. The stability of equine dominance hierarchies and the effects of kinship, proximity and foaling status on hierarchy rank. Appl. Anim. Behav. Sci. 1986, 16, 121-130. [CrossRef]

40. Croft, D.P.; James, R.; Krause, J. Exploring Animal Social Networks; Princeton University Press: Princeton, NJ, USA, 2008.

41. Heitor, F.; Oom, M.d.M.; Vicente, L. Social relationships in a herd of Sorraia horses. Behav. Process. 2006, 73, 170-177. [CrossRef]

42. Granquist, S.M.; Thorhallsdottir, A.G.; Sigurjonsdottir, H. The effect of stallions on social interactions in domestic and semi feral harems. Appl. Anim. Behav. Sci. 2012, 141, 49-56. [CrossRef]

43. Kaseda, Y.; Khalil, A.M.; Ogawa, H. Harem stability and reproductive success of Misaki feral mares. Equine Vet. J. 1995, 27, 368-372. [CrossRef]

44. Kaseda, Y. Seasonal changes in time spent grazing and resting of misaki horses. Nihon Chikusan Gakkaiho 1983, 54, 464-469. [CrossRef]

45. Kaseda, Y.; Khalil, A.M. Harem size reproductive success of stallions in Misaki feral horses. Appl. Anim. Behav. Sci. 1996, 47, 163-173. [CrossRef]

46. Kaseda, Y.; Ogawa, H.; Khalil, A.M. Causes of natal dispersal and emigration and their effects on harem formation in Misaki feral horses. Equine Vet. J. 1997, 29, 262-266. [CrossRef] [PubMed]

47. Martin, P.; Bateson, P. Measuring Behaviour; Cambridge University Press: Cambridge, UK, 2007.

48. Fureix, C.; Bourjade, M.; Henry, S.; Sankey, C.; Hausberger, M. Exploring aggression regulation in managed groups of horses Equus caballus. Appl. Anim. Behav. Sci. 2012, 138, 216-228. [CrossRef]

49. Jameson, K.A.; Appleby, M.C.; Freeman, L.C. Finding an appropriate order for a hierarchy based on probabilistic dominance. Anim. Behav. 1999, 57, 991-998. [CrossRef] [PubMed]

50. Hemelrijk, C.K. A matrix partial correlation test used in investigations of reciprocity and other social interaction patterns at group level. J. Theor. Biol. 1990, 143, 405-420. [CrossRef]

51. Shimada, M.; Sueur, C. Social play among juvenile wild Japanese macaques (Macaca fuscata) strengthens their social bonds. Am. J. Primatol. 2017, 80, e22728. [CrossRef] [PubMed]

52. Shimizu, H. An introduction to the statistical free software HAD: Suggestions to improve teaching, learning and practice data analysis. J. Media. Inform. Commun. 2016, 1, 59-73.

53. Borgatti, S.P.; Everett, M.G.; Freeman, L.C. UCINET. In Encyclopedia of Social Network Analysis and Mining; Springer: New York, NY, USA, 2018; pp. 3243-3249.

54. Inoue, S.; Yamamoto, S.; Ringhofer, M.; Mendonça, R.S.; Pereira, C.; Hirata, S. Spatial positioning of individuals in a group of feral horses: A case study using drone technology. Mammal. Res. 2018, 64, 249-259. [CrossRef]

55. Gardner, A.; West, S.A. Spite. Curr. Biol. 2006, 16, R662-R664. [CrossRef]

56. Fedurek, P.; Dunbar, R.I.M. What does mutual grooming tell us about why chimpanzees groom? Ethology 2009, 115, 566-575. [CrossRef]

57. Matsuzawa, T. Horse cognition and behavior from the perspective of primatology. Primates 2017, 58, $473-477$. [CrossRef] [PubMed]

(C) 2020 by the authors. Licensee MDPI, Basel, Switzerland. This article is an open access article distributed under the terms and conditions of the Creative Commons Attribution (CC BY) license (http://creativecommons.org/licenses/by/4.0/). 